\title{
Analysis and Evaluation Research on the Influencing Factors of the Development of Local Agricultural Products
}

\author{
Xin Wang ${ }^{1, *}$ \\ ${ }^{1}$ Lanzhou University of Technology , Lanzhou, Gansu, China
}

\begin{abstract}
This article takes the development of agricultural products as the research object, through the analysis and induction of the factors affecting the development of agricultural products, applying the analytic hierarchy process and the fuzzy comprehensive evaluation method, taking the potato products of Ding xi and Lanzhou as examples, collecting relevant data, and verifying the evaluation through comparative analysis. The scientificity and rationality of the evaluation system are verified through comparative analysis.. This article provides reference for studying the factors affecting the development of agricultural products, and at the same time has important guiding significance for the development of local agricultural products.
\end{abstract}

\section{Introduction}

China is a large agricultural country. The diversity of regional soil characteristics, regional differences, and many other influencing factors have created many characteristic agricultural products. At the same time, it also brought huge challenges and pressures to China's agricultural development. Developing agricultural products with local characteristics and taking the road of high-quality and modern agricultural development have become an inevitable choice for China to construct modern agriculture, develop regional agricultural economy, and promote farmers' income ${ }^{[1]}$.

The analysis and evaluation research on the influencing factors of the development of local agricultural products originated from the research on the varieties of agricultural products. Wei Rong and Wang Xiudong believe that to accelerate the development of modern agriculture, it is necessary to change the development mode of the planting industry and seek a reformative way out of the development of the planting industry ${ }^{[2]}$. In the article "Research on Legal Regulations of Agricultural Product Quality", Zhang Meng believes that to accurately grasp the influencing factors that affect the growth of agricultural products, it is necessary to know the conditions for the growth of agricultural products, so as to avoid excessive input of chemical fertilizers, pesticides, etc. To a certain extent. it can greatly improve the quality of agricultural products ${ }^{[3]}$. Jana Némethová, Alena Dubcová and other scholars pointed out in their article that the adjustment of agricultural policy structure has important impacts on the landform, labor force distribution and crop planting in different regions ${ }^{[4]}$, Manuel Gonzalez Di Yass, Fernandez and Arrenada proposed that the quality and safety of agricultural products and quality assurance are the key links ${ }^{[5]}$.

However, the above research is not a quantitative study on the factors affecting the development of agricultural products. This article uses analytic hierarchy process and fuzzy comprehensive evaluation method to determine the weight of each index in the overall evaluation model and establishes an evaluation model of factors affecting the development of local agricultural products, so that it can analyze and evaluate various factors that affect the development of agricultural products more objectively and scientifically. It can overcome the "subjective perception" component in traditional evaluation methods. Therefore, the research method in this article can be used as a reference for future research related to the factors affecting the development of agricultural products.

\section{Materials and Methods}

This article mainly studies the factors affecting the production of different agricultural products due to regional differences. According to the various factors that affect the regional agricultural products found in the literature, the main influencing indicators that affect the development of agricultural products are: technical factors, environmental factors, labor factors and social factors, etc ${ }^{[6]}$. It is planned to use analytic hierarchy process and other methods to analyze which indicators have a more important impact on the development of agricultural products ${ }^{[7]}$. Based on this, The article take agricultural products in a region of Gansu Province as an example, and use the indicators obtained from the analysis to evaluate whether the region is suitable for developing the agricultural product and judge the

\footnotetext{
* Corresponding author: 18215124717@163.com
} 
scientificity and reality of the conclusion. Then, the reasonable measures and suggestions can be given.

\subsection{Model setting}

Based on the analysis of the agricultural situation in Gansu Province, this paper selects 16 representative indicators at five levels: environmental influencing factors, social influencing factors, technical influencing factors, labor influencing factors and economic influencing factors to constitute the factors affecting the development of local agricultural products. The final analyses of the factors are shown in Table 1.

Table 1 Index System of Factors Affecting the Development of Local Agricultural Products

\begin{tabular}{|c|c|}
\hline Criterion layer & Index layer \\
\hline \multirow{5}{*}{ Environmental indicators } & average temperature $(\mathrm{C} 1)$ \\
\hline & annual precipitation (C2) \\
\hline & geographical fitness (C3) \\
\hline & pollution degree ( $\mathrm{C} 4)$ \\
\hline & soil nutrition ( $\mathrm{C} 5)$ \\
\hline \multirow{3}{*}{ Social indicators } & legal support (C6) \\
\hline & government support (C7) \\
\hline & number of service stations (C8) \\
\hline \multirow{5}{*}{ Technical index } & fertilizer dosage (C9) \\
\hline & pesticide dosage ( $\mathrm{C} 10)$ \\
\hline & hormone dosage ( $\mathrm{C} 11)$ \\
\hline & number of agricultural machinery \\
\hline & $(\mathrm{C} 12)$ \\
\hline \multirow[t]{2}{*}{ Labor index } & number of labor $(\mathrm{C} 13)$ \\
\hline & qualities of Workers ( $\mathrm{C} 14)$ \\
\hline
\end{tabular}

Degree of financial policy support

(C16)

\subsection{Construct a judgment matrix}

By issuing questionnaires, the importance of each level and indicators are scored. Then, analyze and process the effective data screened out by the questionnaire to obtain the weights of the criterion-level indicators for pairwise comparison and construct a judgment matrix based on the results.

$$
A=\left[\begin{array}{lllll}
1.00 & 1.61 & 1.72 & 1.59 & 1.39 \\
0.62 & 1.00 & 1.54 & 1.32 & 1.39 \\
0.58 & 0.65 & 1.00 & 1.28 & 1.45 \\
0.63 & 0.76 & 0.78 & 1.00 & 1.61 \\
0.72 & 0.72 & 0.69 & 0.62 & 1.00
\end{array}\right]
$$

After calculation, the judgment matrix satisfies the consistency test. By calculating the weights of all levels of indicators in the indicator system relative to the total target, the composite weight of the indicator system can be calculated at last. The final composite weight are shown in Table 2.

Table 2 Composite weight of the index system

\begin{tabular}{c|c|c}
\hline Criterion layer & Index layer & Composite layer \\
\hline \multirow{2}{*}{$\begin{array}{c}\text { average temperature (C1) } 0.18 \\
\text { annual precipitation (C2) } 0.19\end{array}$} & 0.051 \\
&
\end{tabular}




\begin{tabular}{|c|c|c|}
\hline \multirow{4}{*}{$\begin{array}{c}\text { Environmental } \\
\text { indicators } \\
0.28\end{array}$} & geographical fitness (C3) 0.18 & 0.051 \\
\hline & pollution degree (C4) 0.15 & 0.042 \\
\hline & soil nutrition (C5) 0.35 & 0.098 \\
\hline & legal support（C6） 0.28 & 0.062 \\
\hline \multirow{4}{*}{$\begin{array}{l}\text { Social indicators } \\
0.22\end{array}$} & government support (C7) 0.40 & 0.088 \\
\hline & number of service stations (C8) 0.32 & 0.070 \\
\hline & fertilizer dosage (C9) 0.26 & 0.047 \\
\hline & pesticide dosage ( $\mathrm{C} 10) 0.25$ & 0.045 \\
\hline \multirow{3}{*}{$\begin{array}{c}\text { Technical index } \\
0.18\end{array}$} & hormone dosage ( C11) 0.22 & 0.039 \\
\hline & number of agricultural machinery & 0.048 \\
\hline & $(\mathrm{C} 12) 0.27$ & \\
\hline \multirow{3}{*}{$\begin{array}{l}\text { Labor index } \\
\qquad 0.18\end{array}$} & number of labor (C13) 0.46 & 0.083 \\
\hline & qualities of Workers (C14) 0.54 & 0.097 \\
\hline & willingness of farmers (C15) 0.52 & 0.078 \\
\hline $\begin{array}{c}\text { Economic } \\
\text { Indicators } 0.15\end{array}$ & $\begin{array}{l}\text { Degree of financial policy support } \\
\qquad \text { (C16) } 0.48\end{array}$ & 0.072 \\
\hline
\end{tabular}

\section{Results \& Discussion}

\subsection{Data Sources}

The data in this article comes from the original 2017 and 2019 Statistical Yearbooks which includes Ding xi and Lanzhou. Besides, the 2019 Gansu Statistical Yearbook is also cited.

\subsection{Longitudinal dimension analysis}

Based on the data that has been obtained, a comparative analysis of the potato agricultural products in Ding xi in 2018 and 2016 is carried out. A set of factors can be established,which is represented by the letter $U$, $\mathrm{U}=\{\mathrm{C} 1, \mathrm{C} 2, \cdots \cdots, \mathrm{C} 16\}$.

After normalization, the weight can be obtained as

$$
\begin{aligned}
& \mathrm{W}=(0.036,0.038,0.036,0.030 \text {, } \\
& 0.069,0.055,0.079,0.063 \text {, } \\
& 0.051,0.050,0.044,0.053 \text {, } \\
& 0.091,0.107,0.103,0.095)
\end{aligned}
$$

By consulting the development of potato agricultural products in Ding xi City in 2016, the output of potato agricultural products in Ding xi City in 2016 was 609,939 tons, and then calculated using fuzzy comprehensive evaluation, and compared with the development of agricultural products in 2018 in the time dimension.

the membership degree of each indicator can be obtained as
$\mathrm{R} 1=(0.0312,0.1262,0.0992,0.0082$,

$0.1417,0.0992,0.0992,0.0081$,

$0.0043,0.0057,0.0709,0.0028$,

$0.0340,0.0709,0.0992,0.0992)$

Fuzzy comprehensive evaluation:

$\mathrm{S} 1=\mathrm{W} \times \mathrm{R} 1=0.094$

Then, the membership degree of each indicator can be obtained as

$$
\begin{aligned}
& \mathrm{R} 2=(0.104,0.113,0.097,0.008 \\
& 0.097,0.097,0.097,0.007 \text {, } \\
& 0.005,0.006,0.069,0.003 \text {, } \\
& 0.037,0.069,0.097,0.097)
\end{aligned}
$$

Fuzzy comprehensive evaluation:

$$
\mathrm{S} 2=0.097
$$

The comprehensive evaluation value of $0.094<0.097$ indicates that the growth conditions of agricultural products in 2016 are better than the growth conditions of agricultural products in 2018, and the conditions in 2016 are more suitable for the development of potato agricultural products. The analysis indicators show that the average annual temperature and annual precipitation in Ding xi in 2016 fluctuate greatly compared with 2018, resulting in a difference in the final score. 


\subsection{Horizontal dimension analysis}

By consulting the 2019 Gansu Yearbook, we found that the output of potato agricultural products in Lanzhou in 2018 was 67,810 tons. This article uses a fuzzy comprehensive evaluation method to analyze the potato agricultural products in Ding $\mathrm{xi}$ and the potato agricultural products in Lanzhou in 2018 through spatial comparison analysis. It is calculated and compared with the development of agricultural products in 2018 in the spatial dimension.

the membership degree of each indicator can be obtained as

$$
\begin{aligned}
& R 3=(0.136,0.157,0.088,0.019 \text {, } \\
& 0.053,0.088,0.088,0.036 \text {, } \\
& 0.012,0.007,0.088,0.005 \text {, } \\
& 0.063,0.053,0.053,0.053)
\end{aligned}
$$

Fuzzy comprehensive evaluation:

$$
\mathrm{S} 3=0.067
$$

Because of $\mathrm{S} 3<\mathrm{S} 1$, Ding xi City is more suitable for developing potato agricultural products than Lanzhou City. Analyzing the scores of various indicators, it can be seen that the scores of the four indicators of annual average temperature, annual precipitation, soil nutrition and farmers' willingness are quite different from those of Ding xi City.

Based on the above analysis, the comprehensive conditions for the development of potato agricultural products in Ding xi City in 2018 are slightly inferior to the development conditions for potato agricultural products in 2016. Therefore, different time periods in the same area will affect the growth environment of agricultural products due to various external factors, resulting in agricultural products. Changes in output. In 2018, the comprehensive conditions for the development of potato agricultural products in Ding xi City were better than those in Lanzhou. Therefore, different regions at the same time period will affect the growth of agricultural products and thus affecting the output of agricultural products due to the self-growing conditions and external factors of agricultural products.

\section{Conclusions}

Through the comprehensive application of the analytic hierarchy process and the fuzzy comprehensive flat method, it is calculated that the soil nutrition under the environmental indicators has the most significant impact among the many factors that affect the development of local agricultural products. Therefore, when considering the development of agricultural products in the local area, it should first consider the influencing factor of soil nutrition. Farmer can investigate the content of various trace elements and minerals in the local soil in advance. The soil is rich in various minerals, which can provide for the growth of crops. Natural nutrients can make crops get adequate nutrition during the growth process, thereby improving the quality and yield of agricultural products; Secondly, the quality of workers should be taken into consideration. With the development of the current level of science and technology, the development of agricultural products is no longer a simple planting and breeding model. It also relies on many technical means. Among them, the amount of hormones accounts for The weight is the smallest, and the impact on the development of agricultural products is almost small.

\section{References}

1. Xiao Rong. Regional brand construction of local superior agricultural products[J]. Human Agricultural Sciences. 2018(08):96 99

2. Wei Rong,Wang Xiudong. The production status of main agricultural products in my country's planting industry and countermeasures[J]. Agricultural Economics. 2015(01): 42 44

3. Zhang Meng. Research on the legal regulation of agricultural product quality [D]. Northwest University. 2015.06

4. Jana Némethová,Alena Dubcová, Hilda Kramáreková. The Impacts of the European Union's Common Agricultural Policy on Agriculture in Slovakia/ Dopady společné zemědělské politiky Evropské unie na zemědělství Slovenska[J]. Moravian Geographical Reports,2015,22(4).

5. Manuel González - Díaz, Marta F B, Benito A. Quality assurance mechanisms in agrifood:the case of the Spanish fresh meet sector[J].International Journal of Technology Management and the International Journal of Agricultural Resources Governance and Ecology. 2003, 2(3/4): 82 361

6. Brian G I, William A K.International product differentiation through a country brand:An economic analysis of national branding as a marketing strategy for agricultural products[J]. CATPNC commissioned Paper. 2007: 1 25

7. Liu Yunxiao. Exploration of the factors affecting the quality of agricultural products by soil fertilizers $[\mathrm{J}]$. Friends of Farmers to Become Rich. 2019(04): 125

8. "Gansu Development Yearbook". Gansu Development Yearbook [EB/OL]. .2018 